are excluded and not brought to bear on these challenges. The Sustainable Biosphere project will remain cognizant of all the other current projects that are aimed at various pieces of the sustainable Biosphere imperative. Indeed, the Sustainable Biosphere project will learn from the experience of these projects, and will share results widely among related studies throughout the world.

\section{Products of the Project}

This SCOPE project is designed:

a) to describe the state of knowledge throughout the world about each of the above environmental issues, and

b) to propose a research agenda that will address the highest-priority issues and questions.

These are global issues found throughout the world in both industrialized and less-developed countries. In fact, many of the issues involve interactions between one or more countries with similar or disparate resources. Therefore, the project will be organized on a world-wide basis, but will accommodate differences among the various regions and countries of the globe.

\section{Process to be Used in Conducting the Project}

The actual process of the project will involve workshops in, probably, seven regions of the world that encompass the global variability in cultural/resource/economic interactions. Such a plan will be feasible in the three years of the project. Each workshop will consider the environmental topics enumerated above, but the treatment of these topics will depend upon the characteristics of the region itself. For example, in some parts of the world simplification of ecosystems and even wider ecocomplexes may be a predominant issue, whereas the relationships between cultural values and natural resource utilization may predominate elsewhere.

The regionally-differentiated issues are controlled by combinations of environmental and social characteristics. As an illustration, in some parts of the tropics nutrient turnover rates are relatively rapid, thus determining the allowable long-term farming strategies. Superimposed on this pattern of environmental variability are such social / cultural patterns as individual and communal land-tenure systems. Each regional workshop will be planned to recognize these important patterns. Regardless of these varying emphases, all the workshops will have the charge of synthesizing the relevant state of knowledge on the topics and then proposing a research agenda addressing the highest-priority issues and problems.

\section{Cumulative Database}

As the workshop series proceeds, there will be an everincreasing database of knowledge, data, and recommendations. In this way, the SCOPE project is designed to capture this incremental knowledge and thus share both the similarities and dissimilarities that will have become part of the individual regional workshops. The final synthesis volume should be of unprecedented richness, drawing on the regional workshops to describe the worldwide status of knowledge about sustaining The Biosphere, and putting forth the highest-priority research recommendations both for each region and for the Earth as a whole.

\section{The Challenge Revisited}

This is an ambitious project that is perhaps as complex as any ever attempted by SCOPE. It focuses on defined yet complicated environmental issues, draws simultaneously on the expertise of many disciplines, and is worldwide although accommodating differences among regions of the globe. It is only with this aggressive and bold approach that we can have any real chance of moving beyond the current state of affairs and eventually being able to prescribe a recipe for sustaining The Biosphere for the next and subsequent generations.*

\section{SCOPE SECRETARIAT \\ 51 Boulevard de Montmorency 75016 Paris \\ France.}

* Here should be borne in mind for correlation the International Sustainable Biosphere Initiative of the International Association of Ecology (INTECOL) - see 'A Sustainable Biosphere: The Global Imperative', Ecology International, 1991: 20 Special issue, pp. $1-14$, and, regarding 'Human-caused Soil-ecological Changes and Their Effect on The Biosphere', the incipient project on which a background statement is published on page 197 of the preceding volume of Environmental Conservation. - Ed.

\title{
Recommended Policies for Sustainability of European Forest Resources
}

\section{Introduction}

Europe's forest industries and forest resources are under pressure as never before. Prominent factors include economic recession (decreased demand and lower prices), structural changes in the industry (increased recycling), and damage to forests caused by air pollutants - particularly airborne acids. In the coming decades, changes in climate caused by global warming are expected to add to these pressures. Such circumstances call for a fundamental shift in thinking about the management of Europe's forests and forest industries. New approaches and policies should be based on the principle of sustainable development, defined by the Brundtland Commission as 'development that meets the needs of the present without compromising the ability of future generations to meet their own needs.'

Most European countries have formally accepted the concept of sustainable development, so the problem is to translate this concept into operational policies concerning forest resources. A major impediment to sustainable development of forest resources lies in the application of traditional economic theory to natural resources. Neoclassical economics has been applied successfully to a wide range of problems, but its application to natural resources reveals fundamental inadequacies.

Conventional valuation techniques, based on the concept of efficiency, stress the welfare of current generations, while discounting the costs to future generations. This short-term approach is inimical to the concept of sustainability, which is concerned with equity and the future. Current policy debates about the future of forest resources in Europe are based principally on the criterion of economic efficiency, not sustainability. Such a discussion obscures the question of sustainability and distorts forest policy. 


\section{Consider Non-wood Benefits}

What is urgently needed is a more sophisticated debate than hitherto on forest resources and policy. Policymakers must take into account not just short-term economic benefits, as they do now, but also the less obvious nonwood benefits of forests - such as recreation, wildlife habitat, soil and water protection, microclimate amelioration, and carbon sequestration.

The IIASA Forest Study has attempted to quantify sustainable harvest levels for each country of Europe and to address some, but not all, aspects of the issues of sustainability of forest resources. The Study indicates that the maximum biologically-sustainable harvest-level would be:

$\begin{array}{lc}\text { Western Europe } & 410-435 \\ \text { Eastern Europe } & 125-130 \\ \text { European former USSR area } & 320 \\ \text { Total } & 855-885\end{array}$

The lower values are based on existing forest-land area; the higher values assume increases in forested areas up to the year 2020, primarily from the reforestation of marginal agricultural lands. These estimates are a theoretical maximum; they assume no negative effects from air pollutants or climate change. If we count in the level of air pollutants that would result from full implementation of current agreements to restrict pollution, the total biological sustainable harvest would decrease, by about one-seventh, to $750-780$ million $\mathrm{m}^{3}$ per year. Current harvest levels are around 680 million $\mathrm{m}^{3}$ per year.

\section{Sources Currently Adequate but Pollutants Devastating}

We thus see that there is no immediate problem in satisfying demand. The situation, however, is expected to change dramatically in the coming decades. Increased demand for wood and wood products is expected to lead within 20 years to a deficit of some 40 million $\mathrm{m}^{3}$ per year (assuming no air pollution) or 150 million $\mathrm{m}^{3}$ per year if air pollution is taken into account. The IIASA Forest Study has estimated that damage to forests from air pollutants costs Europe nearly US $\$ 30$ thousand millions per year. This valuation takes into account most, but not all, aspects of sustainability. It is probably an underestimate of the true loss.

If European nations are to enjoy sustained use of healthy, economically productive forests, they must greatly increase current efforts to reduce emissions of airborne pollutants. Sustainability would be possible only if we:

- reduce emissions of sulphur, nitrogen, and concentrations of ozone, as much as possible over as large an area as possible;

- restructure existing energy systems - installing scrubbing equipment on existing systems will not suffice.

These goals will not be achieved easily or cheaply. Current efforts to reduce $\mathrm{SO}_{2}$ and $\mathrm{NO}_{\mathrm{x}}$ emissions cost Europe around US $\$ 16$ thousand millions per year; to achieve forest sustainability would require expenditures of some US $\$ 90$ thousand millions per year. Such an expenditure would dramatically improve the quality of air throughout Europe, and clearly forests would not be the only beneficiaries.

In addition to reducing air pollution, greater attention must be paid to forest management. Silvicultural practices in Europe seldom live up to stated national policies; rotation periods are typically too long, thinnings too few.
Continuation of current silvicultural practices will further decrease sustainability and hasten the decline of European forests. Therefore, all European countries are urged to:

- implement efficient policies on forest management as rapidly as possible in order to increase the sustainability and vitality of forest resources.

Non-wood Benefits of Sustainability

Forest owners, industry, and the general public, are attaching increased importance to non-wood benefits of sustainability - such as recreation, wildlife habitat, soil and water protection, microclimate amelioration, carbon sequestration, etc. Policies to address these non-wood benefits must be based on sound quantitative analyses, but there is a serious scarcity of appropriate data on non-wood benefits. The nations of Europe are urged to:

- collect systematic data on non-wood benefits from a sustainability viewpoint;

- based on these data define and quantify goals designed to achieve a reasonable balance between plentiful, healthy, attractive forests and a sound forestproducts sector contributing to national wealth and well-being; and

- make a firm commitment to this sustainable balance and to state explicity that non-economic forest-policy goals must not be sacrificed under short-term economic pressures, even during a recession.

To formulate policies leading to sustainable development, policymakers must come to grips with the contradictions between traditional economics and sustainability. European countries are therefore urged to:

- review concepts of valuation currently applied to forest resources with the goal of incorporating sustainability into decision-making; and

- establish ecological economics centres which should seek to refine the economics of public policymaking so as to take account of both the positive and negative consequences of development of natural resources, including forests.

\section{Unsustainability of Europe Alone}

Europe cannot achieve sustainability in isolation. The Earth's atmosphere is expected to warm significantly in coming decades, causing serious changes in climate and raising of sea-level. While there are still uncertainties about the extent and nature of climate changes, based on current knowledge we can anticipate a severe decline in productivity of forests and a redistribution of forest ecosystems and ecocomplexes in Europe. The effects will be especially severe if climate change is accompanied by high emissions of air pollutants: the cumulative stress on some forest ecosystems, notably in mountainous regions, could be little short of disastrous.

In short, efforts to achieve sustainability in Europe could be fruitless unless sustainability is achieved in the world as a whole. The countries of Europe are therefore urged to work with other nations and international organizations on problems such as the development of supportable world population, resource-efficient technologies, tropical deforestation, and global economic approaches based on Nature's carrying-capacity.

\footnotetext{
Sten NiLsson, Professor \& Leader

Forest Resources Project

International Institute for Applied Systems Analysis A-2361 Laxenburg

Austria.
} 